\title{
Comparing the Life Quality of the Students in the Faculty of Sports Sciences and the Faculty of Education
}

\author{
Tahir Kiliç ${ }^{1}$, Nazmi Bayköse ${ }^{1}$, Kıvılcım Kaplan ${ }^{1}$ \\ ${ }^{1}$ Akdeniz University Faculty of Sport Sciences, Turkey \\ Correspondence: Nazmi Bayköse, Faculty of Sport Sciences, Akdeniz University, Turkey.
}

Received: May 8, 2018

Accepted: July 2, 2018

Online Published: July 4, 2018

doi:10.11114/jets.v6i8.3413

URL: https://doi.org/10.11114/jets.v6i8.3413

\begin{abstract}
Objective of this study is to compare the life quality of the students in the Faculty of Sports Sciences and the Faculty of Education in Akdeniz University for the education year 2017-2018. The sample of the research study was composed of 895 students (448 female, 447 male) from Akdeniz University, Faculty of Sports Sciences and the Faculty of Education. The life qualityes of the studentes were evaluated according to the Turkish brief questionnaire (WOQOL-BREF TR) of WHOQOL life quality scale. WHOQOL life quality scale was developed by WOQOL group. WOQOL-BREF, a shorter form of this test, which involved 100 items, was developed by the same group and it was interpreted into Turkish afterwards, by Fidaner et al. (1999). Originally composed of 26 items, this scale's Turkish version was comprised of 27 items. The data was analyzed via SPSS package program. In order to determine the differences in socio-demographic features of the participant students, one-way variance analysis (ANOVA) was used, and for observing the group differences, Tukey HSD and Independent Sample T Test were used. When the results of the Life Quality Scale of the students were analyzed, it was observed that there was statistically no significant difference in any sub-dimension of the life satisfaction, including the life satisfaction total points.
\end{abstract}

Keywords: life quality, sports sciences, faculty of education

\section{Introduction}

Change has always played its role in technology and life as in the developing and changing world, thus individuals and societies have been influenced from this situation as well. This reality created the term life quality for the individuals, who have been affected. Considering the pace of the globalization of the world we live in today, it is suggested that education should be handled from a different point of view and its quality should be re-evaluated in each passing day. One of the most important functions of education is to raise the students in tune with the time and according to the needs of the society. The schools, which left behind the outmoded information transfer responsibility, assume the role to prepare the students to life and to socialize them. It is considered an effective and important factor to have a high level of school life quality in order to assume this role, to be in tune with the time, and help the students improve academically, socially, and individually (Alaca, 2011; Alpkaya, 2010; İnal, 2009; Argon and Kösterelioğlu, 2009).

What defines a human, a subject, or an experience in terms of characteristics, and what measures and evaluates its distinctive superiority from other things is called as quality. In other words, quality is a characteristic of an individual defining his/her nature in intellectual and moral domain (Zorba, 2009b). Life quality is related with self-development, enrichment of personal life, and reaching his/her goalss. Quality life is questioning oneself, knowing oneself, and rendering his/her life peaceful, balanced, and coherent. Also considered as the subjective emotion of an individual about changing his/her life for the better, life quality does not have a single universally accepted definition (Zorba, 2004a; Kalaycı and Özdemir, 2013).

The life quality is a new and wide concept, which has been suggested in recent past and which gradually, gains importance. Therefore, it is in the field of interest of almost all of scientific disciplines, every life practice, and every activity in the society. Thus, different disciplines developed different definitions according to their area of interest (Tekeli 2010; Optik, 2004). In a general sense, life quality is comprised of components such as life satisfaction, subjective wellness, happiness, functional competence, and social competence. It is a concept depicting the personal reactions given to the illnesses, which define the level of individual satisfaction that can be obtained in the living conditions, and reactions given to physical, mental, and societal effects of the daily life (Öksüz \& Malhan, 2005). 
While being defined as individual response given to the physical, mental, and social effects of problems that are influencing individual happiness in a certain living space, life quality involves subjective satisfaction regarding certain aspects of life, as well (Beal, 2004).

Studies on the life quality of the young, state that the responsibility of the schools is "to raise each student as an independent individual of a democratic and pluralistic society" rather than transferring information or teaching them learning skills. In this context, the students are learning socially accepted language and behaviors, communicating with adults and their peers, societal norms, taboos, rules and regulations in the schools (Rowland, 2003).

World Health Organization (WHO) correlated the life quality with the cultural life space of the individuals. There is life perception in it, as well. In the life quality definition of WHO, there are six domains that are including features related with physical health, psychological condition, independence level, social relations, environmental features, and spirituality.

When the classification of the World Health Organization regarding the life quality is examined, it is observed that there is a group of physical problems affecting the daily life and functions of an individual such as pain, discomfort, exhaustion, tiredness, sleep, and rest. For the psychological condition, body image, positive or negative opinions, memory, concentration, and self-confidence elements are affecting one's life quality. Independence level is handled as another life quality category. In the independence level, self-functioning of an individual, mobility, working capacity, and addiction to drugs or treatment are addressed. For the social relations, individual relations, social activity, and sexual relations are included. In the environmental features, house and its environs, security, financial sources, physical environment quality, access to new documents and information, and access to the health services are evaluated. Beliefs and freedom of belief are among the important elements such as the others, which influence the life quality perceptions of the individuals (Turgut, 2010; Arslantaş, 2006; Bilgiç, 2009).

The perception regarding psychological, physical, social, individual, and monetary welfare of an individual, which surround the life environment of him/her, might amount to life quality, as well. Actually, these main categories are a summary of life parts of individuals, in a sense. It is possible to mention that there are elements decreasing the life quality of an individual if he/she evaluates his/her life quality in a negative sense, if the perception is negative, and if the individual considers his/her life quality as low. In this context, the cases decreasing the life quality can be listed as follows:

"Being unable to meet the basic needs as demanded influences the life quality negatively. One's evaluating himself / herself physically negative also decreases the life quality.

One's showing no interest in himself/herself and being unable to keep oneself up in the daily life influences the life quality perception negatively. Feeling tired always, acute and chronic health problems affect life quality perception in a negative sense. If the sexual life of an individual is poor, and he/she has problems in this field based on health and mental reasons, the life quality perception decreases. If one has concerns for the future, and despair about his/her expectations, his/her life quality perception decreases."

Contrary to the elements that are negatively influencing the life quality, there are also cases that are increasing the satisfaction level and life quality of an individual (Doğanay and Sar1, 2006). In this regard, the causes influencing the life quality positively are as follows:

"One's feeling himself/herself secure in terms of economic and social aspects increases the life quality perception." Keeping up the daily life without anxiety about security has a positive effect on the life quality. Living a comfortable and luxurious life increases the life quality.

Physical activity and sport notions are elements with positive influences in the literature of life quality, as well. In a meta-analysis research study conducted by Netz et al. (2005) on the relation between psychological wellness and physical activity in elderly people, it was recorded that moderate physical activity is significantly relevant to particularly psychological wellness, physical self-efficiency, and self-perception in the old people. In another research study conducted in France by Vuillemin et al. (2005), the relation between the life quality and physical activity was examined on 2333 male and 3321 female young adults. At the end of the multi way analyses of variance, it was determined that physical activity level for females was significantly relevant to all sub-dimensions of life quality (physical functionality, physical role, mental health, emotional role, social disfunctionality, fitness, general health) except physical pains. According to this research study, life quality of the females and males, who participated to the physical activities in suggested levels, were determined to be higher compared to the group who did not participate. It was determined that high-level physical activity had a determinant effect mostly on fitness dimension of life quality, and second mostly on physical functionality dimension (Vuillemin et al., 2005). In another research study "Examining the physical activity and life quality differences between male and female young adults" conducted in our country by Genç et al. (2011), it was reported that high-level activity, moderate activity, total physical activity, SF-36 physical and mental health points of males were determined to be higher than females. It was also determined that there was statistically no significant difference among the percentages of 
low-level, moderate, and high-level physical activity levels of males and females.

In accordance with abovementioned information, based on gender and faculty variables, the objective of this study is to examine the life quality levels of sports science students, who are receiving education in an intense physical activity program, and the students of faculty of education, who receive education in a lower physical activity program compared to the faculty of sports sciences. In this context, answers were sought for the following questions;

1. Is the life quality of the faculty of sports sciences students higher than the faculty of education students?

2. Is there statistically significant difference between the life quality of the male and female students?

\section{Method}

\subsection{The Model of the Study}

This research study is a descriptive one, which benefited from the scanning model. Scanning model is the research approach that aims to describe a past or present case as is (Karasar, 1998).

\subsection{Research Group}

Totally 895 students participated in the study, 448 of whom were females $\left(\mathrm{M}_{\mathrm{Age}}=20,85 \pm 2,32\right)$ and 447 of whom were males $\left(\mathrm{M}_{\mathrm{Age}}=20,78 \pm 2,35\right)$.

Table 1. Distribution of students according to gender variables

\begin{tabular}{clll}
\hline & & $\mathrm{n}$ & $\%$ \\
Gender & Female & 448 & 50,1 \\
& Male & 447 & 49,9 \\
& Total & 895 & 100,0 \\
\hline
\end{tabular}

As is seen on Table 1, when the distribution of participants are examined according to the gender variable, it is observed that the females are $50,1 \%$ and the males are $49,9 \%$ of the total participants.

Table 2. Distribution of students according to faculty variables

\begin{tabular}{llll}
\hline & & $\mathrm{n}$ & $\%$ \\
Faculty & Faculty of Education & 516 & 57,7 \\
& Faculty of Sports Sciences & 379 & 42,3 \\
& Total & 895 & 100,0 \\
\hline
\end{tabular}

As is seen on Table 2, when the distribution of participants are examined according to the faculty variable, it is observed that the students from faculty of education are $57,7 \%$ and the students from faculty of sports sciences are $42,3 \%$ of the total participants.

\subsection{Data Collection Tools}

In collection of the data, World Health Organization Life Quality Brief Questionnaire and personal information form created by the researchers were used.

\subsubsection{World Health Organization QOL-BREF (WHOQOL-BREF) Questionnaire}

The life quality of the students was evaluated by means of the Turkish brief questionnaire (WOQOL-BREF TR) of WHOQOL-100 life quality scale. WHOQOL life quality scale was developed by the World Health Organization. WOQOL-BREF, a shorter form of the main test, which involved 100 items, was developed by the same group and originally composed of 26 items. This scale's Turkish version was comprised of 27 items. $27^{\text {th }}$ question is a national one. Validity and reliability tests of the scale were conducted by Eser et al. (1999). It questions the life quality in four different dimensions. The dimensions were separated considering that they described an independent life quality from each other. These dimensions; $1^{\text {st }}$ dimension: Physical Health, $2^{\text {nd }}$ Dimension: Psychological Health, $3^{\text {rd }}$ Dimension: Social Relations, $4^{\text {th }}$ Dimension: Environmental Health domain. The domain scores are in between 4-20. The higher the score, the higher the life quality (Oliver, 1997).

\subsubsection{Personal Information Form}

In the personal information form, which was created by the researchers, there are open-ended age, faculty, and gender questions.

\subsection{Data Analysis}

The data of the research study was analyzed in the SPSS program. In order to determine the test to apply to the data, the distribution normality of the variables were examined by means of Kolmogorov-Smirnov test, and it was determined that the distribution $(p>0,05)$ was normal. Independent Sample $T$ test was used in order to determine the differences between the life qualities mean scores of the socio-demographic features of the participant students. The significance level was determined as $\mathrm{p}<.05$. 


\section{Results}

Life quality levels of the participants according to gender and faculty variable are seen on the Scheme 1.

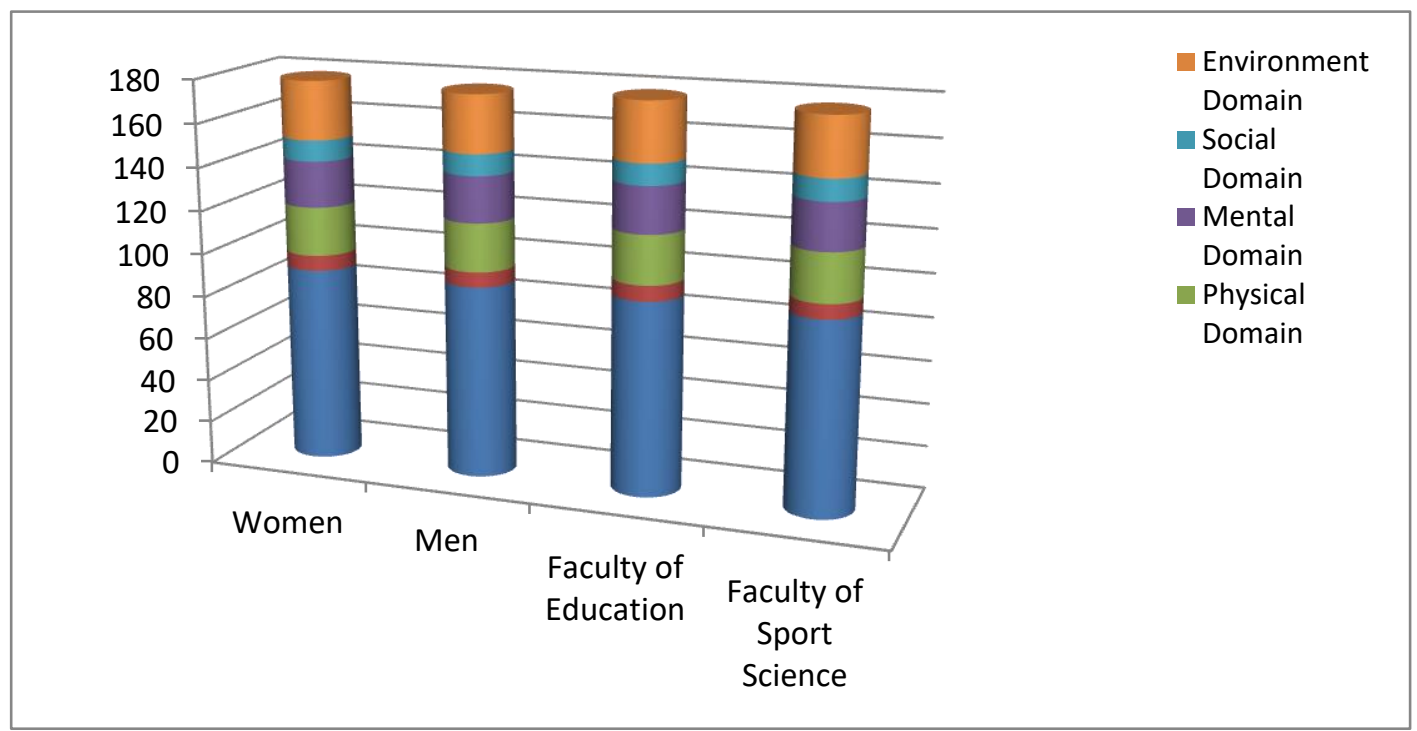

Scheme 1. Based on the Gender and Faculty Variables, Distribution of the Scores Participants Gained From the Life Quality Sub-Dimensions

Table 3. Results Regarding the Life Quality Levels of the Students Based on Gender Variable

\begin{tabular}{llccccc}
\hline \multirow{3}{*}{ Total Score } & Gender & $\mathrm{N}$ & $\mathrm{M}$ Mean & $\mathrm{S} . \mathrm{d}$ & $\mathrm{t}$ & $\mathrm{p}$ \\
& Female & 448 & 90,5290 & 10,28167 & 1,323 & 0,186 \\
General Health & Male & 447 & 89,6264 & 10,13083 & & \\
& Female & 448 & 7,1205 & 1,42170 & 1,656 & 0,098 \\
Physical Domain & Male & 447 & 6,9664 & 1,36130 & & \\
& Female & 448 & 22,5491 & 2,88672 & 1,242 & 0,214 \\
Mental Domain & Male & 447 & 22,3020 & 3,06076 & & \\
& Female & 448 & 21,3571 & 2,88515 & 0,054 & 0,957 \\
Social Domain & Male & 447 & 21,3468 & 2,82178 & & \\
& Female & 448 & 9,6875 & 2,26749 & $-0,600$ & 0,548 \\
Environment Domain & Male & 447 & 9,7785 & 2,26846 & & \\
& Female & 448 & 27,0670 & 4,34939 & 1,831 & 0,067 \\
& Male & 447 & 26,5369 & 4,31109 & & \\
\hline
\end{tabular}

When Table 3 is examined, it is observed that the participants have similar mean scores of life quality based on gender variable. 
Table 4. Results Regarding the Life Quality Levels of the Students Based on Faculty Variable

\begin{tabular}{lllllll}
\hline \multirow{2}{*}{ Total Score } & Faculty & $\mathrm{N}$ & $\mathrm{Mean}$ & $\mathrm{S} . \mathrm{d}$ & $\mathrm{t}$ & $\mathrm{p}$ \\
& Faculty of Education & 516 & 90,3062 & 10,00365 & 0,774 & 0,436 \\
& Faculty of Sports Sciences & 379 & 89,7678 & 10,49182 & & \\
General Health & Faculty of Education & 516 & 7,1880 & 1,36443 & 3,625 & 0,000 \\
& Faculty of Sports Sciences & 379 & 6,8470 & 1,40965 & & \\
Physical Domain & Faculty of Education & 516 & 22,4709 & 2,88638 & 0,525 & 0,600 \\
& Faculty of Sports Sciences & 379 & 22,3641 & 3,09623 & & \\
Mental Domain & Faculty of Education & 516 & 21,3236 & 2,79978 & $-0,344$ & 0,731 \\
& Faculty of Sports Sciences & 379 & 21,3905 & 2,92508 & & \\
Social Domain & Faculty of Education & 516 & 9,7558 & 2,27661 & 0,352 & 0,725 \\
& Faculty of Sports Sciences & 379 & 9,7018 & 2,25686 & & \\
Environment Domain & Faculty of Education & 516 & 26,8682 & 4,28160 & 0,529 & 0,597 \\
& Faculty of Sports Sciences & 379 & 26,7124 & 4,41308 & & \\
& & & & & &
\end{tabular}

When Table 4 is examined, it is determined that there was statistically no significant difference among the scores the students gained from the Life Quality Scale in physical health, mental health, social domain, and environment domain. The students of the faculty of Education have similar scores with the students of the faculty of Sports Sciences as per the Life Quality Scale results. For the life quality total scores; the students of faculty of Education $(90,3062 \pm 10,01)$ have similar means with the students of faculty of Sports Sciences $(89,7678 \pm 10,49)$. In only general health sub-dimension; the students of faculty of Education $(7,19 \pm 2,28)$ have not similar means with the students of faculty of Sports Sciences $(6,85 \pm 2,26)$. In the physical domain sub-dimension; the students of faculty of Education $(22,47 \pm 2,89)$ have similar means with the students of faculty of Sports Sciences $(22,36 \pm 3,10)$. In the mental domain sub-dimension; the students of faculty of Education $(21,32 \pm 2,80)$ have similar means with the students of faculty of Sports Sciences $(21,39 \pm 2,92)$. In the social domain sub-dimension; the students of faculty of Education $(9,76 \pm 2,28)$ have similar means with the students of faculty of Sports Sciences $(9,70 \pm 2,26)$. In the environmental domain sub-dimension; the students of the faculty of Education and other faculties $(26,87 \pm 4,28)$ have higher means from the students of faculty of Sports Sciences $(26,71 \pm 4,41)$.

\section{Discussion}

According to the results of this research study, it is observed that the life quality levels of the participants based on gender variable have similar means. It was determined that there was statistically significant difference among the scores the students gained from the Life Quality Scale in general health. Additionally it was determined that there was statistically no significant difference among the scores the students gained from the Life Quality Scale in physical health, mental health, social domain, and environment domain. The students of the faculty of Education had similar scores with the students of the faculty of Sports Sciences as per the Life Quality Scale results. When the relevant literature is examined, in a research study conducted on middle-aged individuals by Vatansever et al. (2015), it was reported that there was statistically no significant difference in terms of gender variable. In this respect, the findings of the research study conducted by Vatansever et al. (2015) support our study. In another research study conducted on the sample of physical education teachers and other branch teachers by Karagün (2016), it was reported that there was statistically no significant difference concerning gender variable except for the mental domain sub-dimension. In this respect, the findings of the research study conducted by Karagün (2016) partly support our study.

In the life quality total score, the students from the faculty of Education have similar scores with the students from the faculty of Sports Sciences. For the general health sub-dimension, the students from the faculty of Education have similar means with the students from the faculty of Sports Sciences. For the physical domain sub-dimension, the students from the faculty of Education have similar means with the students from the faculty of Sports Sciences. As per the mental domain sub-dimension, the students from the faculty of Education have similar means with the students from the faculty of Sports Sciences. For the social domain sub-dimension, the students from the faculty of Education have similar means with the students from the faculty of Sports Sciences. When the scores for the environment sub-dimension are examined, it is realized that the students from the faculty of Education and other faculties have a higher mean compared to the students from the faculty of Sports Sciences.

In line with the objective of the study, it is useful to examine the results of the relevant literature, even though the curriculum content of the sports sciences students has an intense physical activity. In this context, in a research study 
conducted on university students by Ölçücü et al. (2015), it was stated that $36 \%$ of the students were active in sufficient level, $43 \%$ of them were active in low level, and $21 \%$ is not at all active. Similar results were obtained in the study conducted by Savc1 et al. (2006). According to these research studies, it can be mentioned that the physical activity levels of the students in the Faculty of Sports Sciences is higher compared to the students from other faculties.

In a study, which examined "physical activity and life quality differences between male and female young adults", conducted by Genç et al. (2011), it was reported that high level activity, moderate activity, total physical activity, and SF-36 physical and mental health results of males were higher compared to the females. In this perspective, the findings of the study conducted by Genç et al. (2011) contradict to our research findings.

In another research study, conducted by Vuillemin et al. (2005), the relation between the life quality and physical activity was examined on 2333 males and 3321 females in France. At the end of the multi way analyses of variance, it was determined that physical activity level was correlated with all of the sub-domains of the life quality (physical functionality, physical role, mental health, emotional role, social functionality, fitness, and general health), except for the physical domain. It was determined in this study that the life quality scores of the males and females, who participated in physical activity, were higher compared to the group, who did not participate. It can be mentioned that the findings of the study conducted by Vuillemin et al. (2005), contradict to our research study.

Another study, the dissertation of Telatar (2007), was focused on the life quality and risky behaviors of 20-24 year-old males working in industrial workplaces. According to this study, some facts have positive effects on the life quality such as having a positive general health perception, performing regular physical activity, commuting on foot, increased daily sleeping hours, increased monthly wages, making friendships disregarding the gender, smoking, being married, having a normal body-mass index based-on statement, having good relationships with workers and friends in the workplace, playing no gambles, and not having been exposed to violence in the last one year. Moreover, attitudes, which are defined as risky behaviors, such as not wearing seat belt in car, having sexual relation for money, committing violence in the last one year, and carrying a gun in the last one month make the young perceive a higher life quality level (Telatar, 2007). Under the light of abovementioned information, there are findings in the relevant literature supporting that physical activity has positive effects on the life quality. However, in theory, it is observed that other factors can also be effective on the life quality other than physical activity, which has a positive influence on the life quality. Our research results are parallel to the findings of other studies that examine the quality of life in high schools according to student perceptions (Durmaz, 2008).

As the conclusion, one of the main limitations for our study was that physical activity level correlated to the life quality level was not included in research studies in the relevant literature. It is because without any information about the physical activity level, it is more difficult to explain the statistical similarity in terms of life quality. It can be mentioned that a result was obtained with similar life quality in terms of both gender and faculty variables. It can be suggested that further studies be conducted removing the limitations mentioned in this study.

\section{References}

Alaca, F. (2011). Relation between school life quality perception and school belonging sense in bilingual and non-bilingual students. (Unpublished Master's Thesis). Çukurova University, Adana.

Alpkaya, G. (2010). The effect of feminine-masculine characteristics of the school principals on the school life quality. (Unpublished Master's Thesis). Uşak University, Uşak.

Argon, T., \& Kösterelioğlu, M. A. (2009). The perceptions of the university students concerning university life quality and faculty culture. Journal of Electronic Social Sciences, 8(30), 43-61.

Arslantaş, D., Metintaş, S., Ünsal, A., \& Kalyoncu, C. (2006). Life quality in the elderly of the Eskişehir Mahmudiye district. Journal of Osmangazi Medicine, 28(2), 81-89.

Bilgiç, S. (2009). Examining the relation between the school quality perceptions of the primary school students and the variables of empathetic class atmosphere and loyalty to friends (Unpublished Master's Thesis). Çukurova University. Adana.

Doğanay, A., \& Sarı, M. (2006). Within the framework of democratic life culture, evaluation of the preceptions of the students concerning the life quality in the university: Çukurova University example. Journal of Turkish Education Sciences, 4(2), 107-128.

Durmaz, A. (2008). School Life Quality in the HIgh Schools. Trakya University, Institute of Education Sciences. Edirne.

Eser, E., Fidaner,H., Fidaner, C., Eser, S. Y., Elbi, H., \& Göker, E. (1999). Psychometric Qualifications of WHOQOL-100 and WHOQOL-BREF. Psychiatry Psychology Psychopharmacology (3P) Magazine, 7(Suppl 2), $23-40$ 
Genç, A., Şener, Ü., Karabacak, H., \& Üçok, K. (2011). Investigation of physical activity and life quality differences between male and female young adults. Journal of Kocatepe Medical, 12, 145-150.

Kalayc1, H., \& Özdemir, M. (2013). The effect of the high school students' perceptions about the quality of the school life on the loyalty to school. Gazi University Journal of Gazi Education Faculty, 33(2), 293-315.

Karagün, E. (2016). A Research On The Life Quality Of Physical Education Teachers And Other Branch Teachers. Kastamonu Education Journal, 24(1). 1-12.

Öksüz, E., \& Malhan, S. (2005). Qualitymeter of health-based life quality, Başkent University Publications Ankara, 2005, 2 .

Oktik, N. (2004). Life and life quality in the nursing home, Muğla example. Muğla University Publications. Muğla, 21.

Ölçücü, B., Vatansever, Ş., Özcan, G., Çelik, A., \& Paktaş, Y. (2015). Physical activity level and depression anxiety relation in university students. Uluslararası Türk Eğitim Bilimleri Dergisi (International Turkish Education Sciences Magazine), 3(4), 294-303.

Oliver, M. (1997). WHOQOL-Bref. University of Washington Seattle, United States of America, U.S. Version, 5-31.

Rowland, S. (2003). Teaching for Democracy in Higher Education,Teaching in Higher Education, 8(1), 89-101, https://doi.org/10.1080/1356251032000052348

Savcı, S., Öztürk, M., Arıkan, H., İnal, İ. D., \& Tokgözoğlu, L. (2006). Physical activity levels of the university students. Turkish Cardiology Archieve, 34(3), 166-172.

Tekeli, İ. (2010). Writing on daily life, life quality, and localization, Tarih Vakfı Yurt Yayınları (History Association Yurt Publications), İstanbul, 84.

Telatar, T. G. (2007). Determining life quality and risky behaviors of the 20-24 year-old males working in the industry. Dissertation, Hacettepe University, Medical Faculty, Department of Public Health, Ankara.

Turgut, M. E. (2010). Job satisfaction and life satisfaction relation and a research on the surgical nurses working in the state hospitals in Istanbul, IÜ (Istanbul University), SBE (Institute of Social Sciences), YYLT (Unpublished Master's Thesis), İstanbul, 41.

Vatansever, Ş., Ölçücü, B., Özcan, G., \& Çelik, A. (2015). The relation between physical activity and life quality in teh middle-aged people. Uluslararası Ĕgitim Bilimleri Dergisi (International Education Sciences Magazine), 2(2), 63-73.

Vuillemin, A., Boini, S., Bertrais, S., Tessier, S., Oppert, J. M., Hercberg S., ... Briancon, S. (2005). Leisure time physical activity and health related quality of life. Preventive Medicine, 41, 562-569. https://doi.org/10.1016/j.ypmed.2005.01.006

Zorba, E. (2004a). Lifelong sports, İstanbul: Marmara Yayınevi (Marmara Publications).

Zorba, E. (2009b). Lifelong sports for everyone. Ankara: HíS (Turkish sport for all federation) Publications.

\section{Copyrights}

Copyright for this article is retained by the author(s), with first publication rights granted to the journal.

This is an open-access article distributed under the terms and conditions of the Creative Commons Attribution license which permits unrestricted use, distribution, and reproduction in any medium, provided the original work is properly cited. 